\title{
Spherical and rod-like dialdehyde cellulose nanocrystals by sodium periodate oxidation: Optimization with double response surface model and templates for silver nanoparticles
}

\author{
F-F. Lu ${ }^{1}, H-Y . Y u^{1,2^{*}}, Y . Z h o u^{1}, J-M . Y a o^{2}$ \\ ${ }^{1}$ The Key Laboratory of Advanced Textile Materials and Manufacturing Technology of Ministry of Education, College of \\ Materials and Textiles, Zhejiang Sci-Tech University, 310018 Hangzhou, China \\ ${ }^{2}$ National Engineering Lab for Textile Fiber Materials \& Processing Technology, Zhejiang Sci-Tech University, \\ 310018 Hangzhou, China
}

Received 12 April 2016; accepted in revised form 30 June 2016

\begin{abstract}
A novel double response surface model is used first time to optimize a regioselective process to prepare spherical dialdehyde cellulose nanocrystals (SDACN) and rod-like dialdehyde cellulose nanocrystals (RDACN) via one-step sodium periodate $\left(\mathrm{NaIO}_{4}\right)$ oxidation. The influence of four preparation factors (solid-liquid ratio, $\mathrm{NaIO}_{4}$ concentration, reaction time and temperature) on the yields and aldehyde contents of the final products were evaluated. For comparison, rod-like cellulose nanocrystals (CN-M and CN-S) were prepared by hydrochloric/formic acid hydrolysis and sulfuric acid hydrolysis, respectively. The RDACN shows high crystallinity of $82 \%$, while SDACN presents low crystallinity due to the high degree of oxidation. Thus, SDACN has poorer thermal stability than RDACN and CN-M, but higher than CN-S. Compared to CN-M, SDACN with higher aldehyde contents as templates is beneficial to deposit more Ag nanoparticles with diameters of $30 \pm 4 \mathrm{~nm}$ and the resultant nanohybrids exhibit good antibacterial activities against both Gram-negative E. coli and Gram-positive $S$. aureus.
\end{abstract}

Keywords: nanomaterials, dialdehyde cellulose nanocrystals, $\mathrm{NaIO}_{4}$ oxidation, response surface model, antibacterial activity

\section{Introduction}

Recently, cellulose nanocrystals (CNs) with various morphologies (rod-like or spherical) isolated from the most abundant cellulosic materials have gained increasing attention in some fields such as antimicrobial packagings [1,2], template for metallic nanoparticles [3], aerogels for wastewater treatment [4], drug delivery [5], and protein immobilization [6] due to their excellent properties, including easily modified functional groups, high specific area, aspect ratios, and outstanding stiffness. As the nanofillers, the requirement of CNs surface group varies with the different applications. The traditional methods like acid hydrolysis [4, 7], enzyme-assisted hydrolysis [8] and mechanical treatments [9] can extract the CNs with hydroxyl groups, which are usually modified into other functional groups for further applications. Recently, CNs with functional groups (carboxyl or aldehyde groups) have been developed by 2,2,6,6-tetramethylpiperidinyl-1-oxyl (TEMPO) [10, 11], ammonium persulfate (APS) [12], two-step approach combined acid hydrolysis and $\mathrm{NaIO}_{4}$ oxidations [13-15], and one-step $\mathrm{NaIO}_{4}$ oxidation [16]. The TEMPO and APS oxidations consume for a long time and the oxidizing agents are toxic $[10,12]$. So that, there are growing interests in the preparation of dialdehyde

"Corresponding author, e-mail: phdyu@,zstu.edu.cn C BME-PT 
cellulose nanocrystal (DACN) by two-step approach $\mathrm{NaIO}_{4}$ oxidation, in which DACN with $50-376 \mathrm{~nm}$ in length and $3-18 \mathrm{~nm}$ in diameter were prepared by the sulfuric acid hydrolysis of fibers (cotton fibers and bleached softwood pulp) and then $\mathrm{NaIO}_{4}$ oxidation [13-15]. However, the two-step approach $\mathrm{NaIO}_{4}$ oxidation was complicated and needed environmental unfriendly acid hydrolysis process that leads to the low yield of DACN. More recently, one-step $\mathrm{NaIO}_{4}$ oxidation was used to fabricate DACN efficiently [16]. Theoretically, the $\mathrm{NaIO}_{4}$ oxidation can selectively convert hydroxyl groups on the cellulose into aldehyde groups and form $\mathrm{CNs}$ by oxidative cleavage between at $\mathrm{C}_{2}$ and $\mathrm{C}_{3}$ bonds of the glucose repeat units $[17,18]$. The aldehyde groups on the DACN surfaces can be used as the binding site for the fluorescent bioimaging [19] and nanohybrid templates [1, 2, 20]. Yang et al. [16] obtained the rodlike DACN with length of 100-200 nm and diameter of $5 \mathrm{~nm}$ by $\mathrm{NaIO}_{4}$ oxidation of sheet from kraft softwood pulp after soaking in the water for 2 days, but the oxidation process needed long reaction time of $96 \mathrm{~h}$ with stirring speed of $105 \mathrm{rpm}$. From above, these mentioned oxidation methods were inefficient and the influence model of reaction conditions on the morphology, yield and aldehyde content of DACN has not been established.

In this work, a novel double response surface model on yield and aldehyde content was established to optimize the regioselective extraction of spherical and rod-like DACN from microcrystalline cellulose by a one-step $\mathrm{NaIO}_{4}$ oxidation method without additives within a shorter reaction time. The morphologies, microstructures and properties of the resultant DACN were investigated, and their potential application as a template for nanohybrids was also evaluated.

\section{Experimental}

\subsection{Materials}

Commercial microcrystalline cellulose (MCC, rubbyshaped fragments with particle size of 15-30 $\mu \mathrm{m}$ ) was purchased from Shanghai Chemical Reagents (Shanghai, China). Sodium periodate $\left(\mathrm{NaIO}_{4}\right)$, silver nitrate $\left(\mathrm{AgNO}_{3}\right)$, hydrochloric acid $(\mathrm{HCl})$, formic acid $(\mathrm{HCOOH})$, sulfuric acid $\left(\mathrm{H}_{2} \mathrm{SO}_{4}\right)$, ammonia solution $\left(\mathrm{NH}_{3} \cdot \mathrm{H}_{2} \mathrm{O}\right)$ and hydroxylamine-hydrochloride $\left(\mathrm{NH}_{2} \mathrm{OH} \cdot \mathrm{HCl}\right)$ were purchased from Hangzhou Mike Chemical Agents Co. Ltd., China. All the chemical reagents and materials were in used as-received without further purification, and the water used in experimental procedures was deionized water (Millipore Milli-Q purification system).

\subsection{Preparation of DACN}

It is well known that the $\mathrm{NaIO}_{4}$ oxidation can selectively convert hydroxyl groups on the cellulose into aldehyde groups and formed CNs by oxidative cleavage between at $\mathrm{C}_{2}$ and $\mathrm{C}_{3}$ bonds of the glucose repeat units. The yield and the aldehyde content of DACN are considered as the important criteria to judge the effectiveness of this method. Thus, a novel double response surface models and an orthogonal experiment with four factors and three levels $\left(\mathrm{L}_{16}(3)^{4}\right.$ array) were carried out to optimize the preparation for DACN. In detail, the DACN was fabricated by $\mathrm{NaIO}_{4}$ oxidation under different conditions (solid-liquid ratio range of 1:25-1:100 [g/mL], $\mathrm{NaIO}_{4}$ solution concentration of $0.1-0.5 \mathrm{M}$, time of $0.5-1.5 \mathrm{~h}$, and temperature of $30-60^{\circ} \mathrm{C}$, shown in Table 1). The detailed process was as follows: $1 \mathrm{~g}$ of MCC was put into $\mathrm{NaIO}_{4}$ solution in $100 \mathrm{~mL}$ flask with continuous stirring. After desired reaction time, the product was collected by centrifugation and freeze-dried for $48 \mathrm{~h}$.

Table 1. The factorial experiments of solid-liquid ratio, $\mathrm{NaIO}_{4}$ concentration, reaction time and temperature

(A: solid-liquid ratio; $\mathrm{B}: \mathrm{NaIO}_{4}$ concentration; $\mathrm{C}$ : reaction time; D: temperature; Y: yield; ADC: aldehyde group content; DO: degree of oxidation; $X_{\mathrm{c}}$ : crystallinity)

\begin{tabular}{|c|c|c|c|c|c|c|c|c|}
\hline Sample NO. & $\begin{array}{c}\mathbf{A} \\
{[\mathbf{g} / \mathbf{m L}]}\end{array}$ & $\begin{array}{c}\mathbf{B} \\
{[\mathbf{M}]}\end{array}$ & $\begin{array}{c}\mathbf{C} \\
{[\mathbf{h}]}\end{array}$ & $\begin{array}{c}\mathbf{D} \\
{\left[{ }^{\circ} \mathbf{C}\right]}\end{array}$ & $\begin{array}{c}\mathbf{Y} \\
{[\mathbf{\%}]}\end{array}$ & $\begin{array}{c}\text { ADC } \\
{[\mathbf{m m o l} / \mathbf{g}]}\end{array}$ & $\mathbf{D O}$ & $\begin{array}{c}\boldsymbol{X}_{\mathbf{c}} \\
{[\mathbf{\%}]}\end{array}$ \\
\hline 1 & $1: 100$ & 0.1 & 0.5 & 30 & 93.2 & 0.5 & 0.04 & 72 \\
\hline 2 & $1: 100$ & 0.25 & 1 & 45 & 74.3 & 3.2 & 0.26 & 81 \\
\hline 3 & $1: 100$ & 0.5 & 1.5 & 60 & 68.4 & 9.8 & 0.80 & 79 \\
\hline 4 & $1: 50$ & 0.1 & 1 & 60 & 84.1 & 3.0 & 0.24 & 80 \\
\hline 5 & $1: 50$ & 0.25 & 1.5 & 30 & 78.4 & 1.6 & 0.13 & 72 \\
\hline 6 & $1: 50$ & 0.5 & 0.5 & 45 & 97.7 & 3.8 & 0.31 & 60 \\
\hline 7 & $1: 25$ & 0.1 & 1.5 & 45 & 86.0 & 1.2 & 0.10 & 67 \\
\hline 8 & $1: 25$ & 0.25 & 0.5 & 60 & 90.8 & 0.7 & 0.06 & 74 \\
\hline 9 & $1: 25$ & 0.5 & 1 & 30 & 91.5 & 2.5 & 0.20 & 72 \\
\hline
\end{tabular}


For comparison, cellulose nanocrystals were prepared by acid hydrolysis from MCC using $64 \mathrm{wt} \%$ $\mathrm{H}_{2} \mathrm{SO}_{4}(\mathrm{CN}-\mathrm{S})$ and $\mathrm{HCI} / \mathrm{HCOOH}$ mixture $(\mathrm{CN}-\mathrm{M})$, respectively, as previously reported $[1,2,7]$.

\subsection{Determination of the aldehyde group content and degree of oxidation}

The aldehyde content was determined by $\mathrm{pH}$ titration of forming $\mathrm{HCl}$ obtained from oxime reaction between the $\mathrm{NH}_{2} \mathrm{OH} \cdot \mathrm{HCl}$ and aldehyde groups of DACN [21]. Firstly, $0.01 \mathrm{M} \mathrm{HCl}$ was added to $20 \mathrm{~mL}$ $\mathrm{NH}_{2} \mathrm{OH} \cdot \mathrm{HCl}$ solution $(0.3 \mathrm{M})$, and a $\mathrm{pH}$ meter was used to monitor the $\mathrm{pH}$ of the solution simultaneously, then a curve for $\mathrm{pH}$ vs. $\mathrm{HCl}$ volume $\left(V_{\mathrm{HCl}}\right)$ was plotted. Next, dried samples (approx. $0.1 \mathrm{~g}$ ) were added to the same solution which was described above, and the mixture was sufficiently stirred for $24 \mathrm{~h}$ at the room temperature, then the $\mathrm{pH}$ of the mixture was measured by the $\mathrm{pH}$ meter at the room temperature. Finally, the $V_{\mathrm{HCl}}[\mathrm{mL}]$ of the reaction was determined from the $\mathrm{pH}$ vs. $V_{\mathrm{HCl}}$ curve, and the aldehyde group content of the sample $[\mathrm{mmol} / \mathrm{g}]$ was calculated as shown in Equation (1):

$$
[\mathrm{CHO}]=V_{\mathrm{HCl}} \cdot \frac{c_{\mathrm{HCl}}}{m_{0}}
$$

where $[\mathrm{CHO}]$ is the aldehyde content $[\mathrm{mmol} / \mathrm{g}], V_{\mathrm{HCl}}$ is the $\mathrm{HCl}$ volume, $c_{\mathrm{HCl}}$ is the concentration of the $\mathrm{HCl}$ aqueous solution, $m_{0}$ is the mass of dried DACNs [g]. The degree of oxidation (DO) of DACNs refers to the average number of hydroxyls oxidized by $\mathrm{NaIO}_{4}$ on the anhydrous glucose unit (AGU) and was determined by Equation (2):

$$
\mathrm{DO}=\frac{[\mathrm{CHO}]}{\frac{2 \cdot m_{0}}{162}}
$$

where $\mathrm{DO}$ is the degree of oxidation, $m_{0}$ is the mass of dried DACNs [g], 162 is the molar mass [g/mol] of AGU, and the value of 2 is the theoretical DO value.

\subsection{Preparation of $\mathrm{CN}-\mathrm{Ag}$ nanoparticles}

The synthesized procedures of $\mathrm{CN}-\mathrm{Ag}$ nanohybrids were according to the previously described method $[1,2]$. In general, the aqueous solution of silver ammonia (silver ammonia aqueous solution was prepared by adding $1 \mathrm{~mL}$ of $25 \%$ ammonia to $100 \mathrm{~mL}$
$\mathrm{AgNO}_{3}(0.85 \mathrm{~g})$ solution. The final stage of ammonia addition was performed dropwise to give a clear solution $[1,2,22]$ ) was mixed with the CNs suspensions (approx. $1.0 \mathrm{~g}$ dry sample), and then heated to $90^{\circ} \mathrm{C}$ for about $20 \mathrm{~min}$. After cooling to the room temperature, the precipitates were washed with deionized water by successive centrifugation to remove the residual silver ammonia and the reaction byproducts. Moreover, the CN-M with formate esters, RDACN and SDACN with aldehyde groups were selected to synthesize $\mathrm{CN}-\mathrm{Ag}$ nanohybrids. The samples were dried and denoted as CN-M-Ag-0.85, SDACN-Ag0.85 and RDACN-Ag- 0.85 , respectively, and the FE-SEM photos were shown below (Figures $7 \mathrm{a}, 7 \mathrm{~b}$ and $7 \mathrm{c})$.

\subsection{Characterization}

The morphologies of the CNs were observed using field-emission scanning electron microscopy (FESEM, JSM-5610; JEOL, Japan) at an acceleration voltage of $1.0 \mathrm{kV}$ at room temperature. Chemical structure of samples was measured on a Nicolet 5700 Fourier transform infrared (FT-IR) spectra and the crystal structure was performed on an X-ray powder diffractometer (XRD, ARL X'RA; Thermo Electron Corp.). The thermal stability test was conducted on samples by using a thermogravimetric analyzer (TGA, Pyris Diamond I; PerkinElmer Corp.) under a nitrogen atmosphere with a heating rate of $20^{\circ} \mathrm{C} / \mathrm{min}$ from room temperature to $600^{\circ} \mathrm{C}$. Particle size of aqueous $\mathrm{CN}$ suspension was tested by the Nano ZS Malvern Zetasizer. E. coli as the model Gram-negative bacteria and $S$. aureus as the model Gram-positive bacteria were chosen to investigate the antimicrobial activities of CN-M-Ag-0.85, SDACN-Ag0.85 and RDACN-Ag- 0.85 nanohybrids as reported in previous literatures $[1,2,20]$.

\section{Results and discussion}

\subsection{Model fitting and optimization}

The orthogonal experiment $\left(\mathrm{L}_{16}(3)^{4}\right.$ array) was carried out with four factors (Table 1), 'A', 'B', 'C', and ' $\mathrm{D}$ ' stand for the solid-liquid ratio, $\mathrm{NaIO}_{4}$ concentration, reaction time and temperature, respectively. From range analysis results of Table 2 and Table 3, it is found that the influencing order of the factors on the yield is $C>D>A>B$, while that on the aldehyde content is $B>A>D>C$. It suggests that the re- 
action time plays an important role in the yield of DACN, while $\mathrm{NaIO}_{4}$ concentration has a significant

Table 2. Analyses of the factorial experiments for yields [\%] (A: solid-liquid ratio; $\mathrm{B}: \mathrm{NaIO}_{4}$ concentration; $\mathrm{C}$ : reaction time; $\mathrm{D}$ : temperature)

\begin{tabular}{|l|c|c|c|c|}
\hline & $\begin{array}{c}\mathbf{A} \\
{[\mathbf{g} / \mathbf{m} \mathbf{L}]}\end{array}$ & $\begin{array}{c}\mathbf{B} \\
{[\mathbf{M}]}\end{array}$ & $\begin{array}{c}\mathbf{C} \\
{[\mathbf{h}]}\end{array}$ & $\begin{array}{c}\mathbf{D} \\
{\left[{ }^{\circ} \mathbf{C}\right]}\end{array}$ \\
\hline $\mathrm{K}_{1}$ & 78.7 & 81.5 & 87.7 & 81.4 \\
\hline $\mathrm{K}_{2}$ & 86.7 & 87.5 & 89.6 & 92.3 \\
\hline $\mathrm{K}_{3}$ & 89.4 & 85.9 & 77.6 & 81.1 \\
\hline $\mathrm{R}$ & 10.7 & 6.0 & 12.0 & 11.2 \\
\hline
\end{tabular}

Priority factor

$\mathrm{C}>\mathrm{D}>\mathrm{A}>\mathrm{B}$

Optimal combination $\mathrm{A}_{3} \mathrm{~B}_{2} \mathrm{C}_{2} \mathrm{D}_{2}$

$\mathrm{K}=\left(\sum\right.$ yield after oxidation of single-factor $) / 3$.

$\mathrm{R}=\mathrm{K}_{\max }-\mathrm{K}_{\min }$.

Table 3. Analyses of the factorial experiments for aldehyde group contents [mmol/g] (A: solid-liquid ratio; B: $\mathrm{NaIO}_{4}$ concentration; $\mathrm{C}$ : reaction time; $\mathrm{D}$ : temperature)

\begin{tabular}{|l|c|c|c|c|}
\hline & $\begin{array}{c}\mathbf{A} \\
{[\mathbf{g} / \mathbf{m L}]}\end{array}$ & $\begin{array}{c}\mathbf{B} \\
{[\mathbf{M}]}\end{array}$ & $\begin{array}{c}\mathbf{C} \\
{[\mathbf{h}]}\end{array}$ & $\begin{array}{c}\mathbf{D} \\
{\left[{ }^{\circ} \mathbf{C}\right]}\end{array}$ \\
\hline $\mathrm{K}_{1}$ & 10.3 & 1.6 & 1.7 & 1.6 \\
\hline $\mathrm{K}_{2}$ & 2.8 & 1.9 & 2.9 & 2.8 \\
\hline $\mathrm{K}_{3}$ & 1.5 & 11.2 & 10.1 & 10.3 \\
\hline $\mathrm{R}$ & 8.8 & 9.6 & 8.4 & 8.7 \\
\hline
\end{tabular}

Priority factor $\quad \mathrm{B}>\mathrm{A}>\mathrm{D}>\mathrm{C}$

Optimal combination $\mathrm{A}_{1} \mathrm{~B}_{3} \mathrm{C}_{3} \mathrm{D}_{3}$

$\mathrm{K}=\left(\sum\right.$ aldehyde content after oxidation of single-factor $) / 3$.

$\mathrm{R}=\mathrm{K}_{\max }-\mathrm{K}_{\min }$.

a)
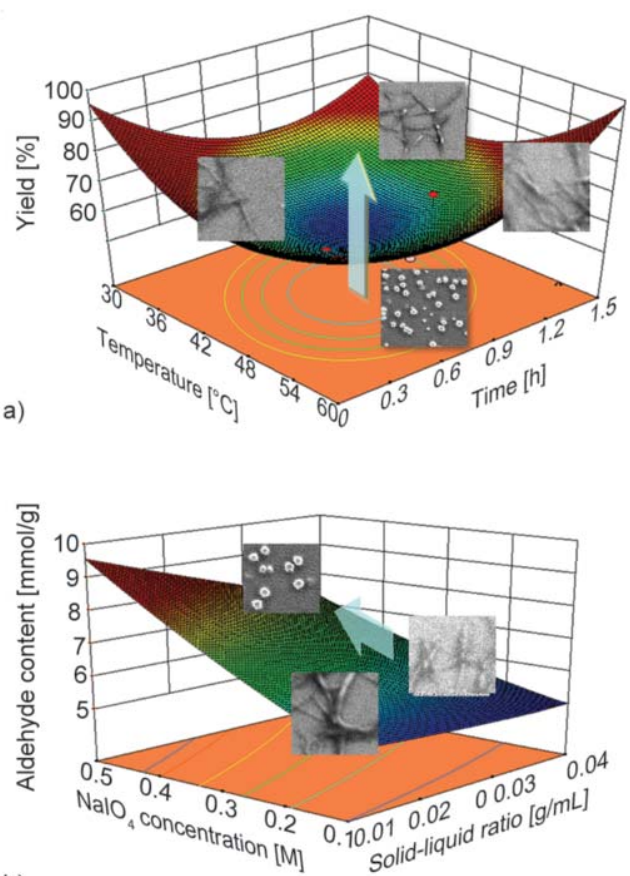

effect on the formation of aldehyde groups. According to the results of the factorial experiments, the optimal combination $\mathrm{A}_{3} \mathrm{~B}_{2} \mathrm{C}_{2} \mathrm{D}_{2}$ was obtained for maximum yields of $97.7 \%$ (the DACN with rod-like shape (see below in Figure 3c) in this condition was denoted as RDACN). Similarly, the optimal combination $\mathrm{A}_{1} \mathrm{~B}_{3} \mathrm{C}_{3} \mathrm{D}_{3}$ was the oxidization conditions for the highest content of aldehyde groups of $9.8 \mathrm{mmol} / \mathrm{g}$ with the highest DO value (about 0.8) (the DACN with spherical shape (see below in Figure $3 b$ ) in this condition was denoted as SDACN). However, when the $\mathrm{NaIO}_{4}$ concentration was increased (over $0.5 \mathrm{M}$ ), the obtained product was becoming completely amorphous (without crystalline region), the XRD spectrum was shown in Figure 4c, which was similar to previous work [23]. In addition, in order to confirm the complete conversion of DACN, the sample 1 (shortest reaction time of $0.5 \mathrm{~h}$, lowest aldehyde content of $0.5 \mathrm{mmol} / \mathrm{g}$ ) was tested in Figure 3d. The results of FE-SEM image and particle size distribution indicated the nanoscale sizes of DACN were achieved even under a short reaction time $(0.5 \mathrm{~h})$.

The mathematical model representing the yield and aldehyde content of DACN against the function of the independent variables within the range under investigation is expressed Equations (3) and (4):
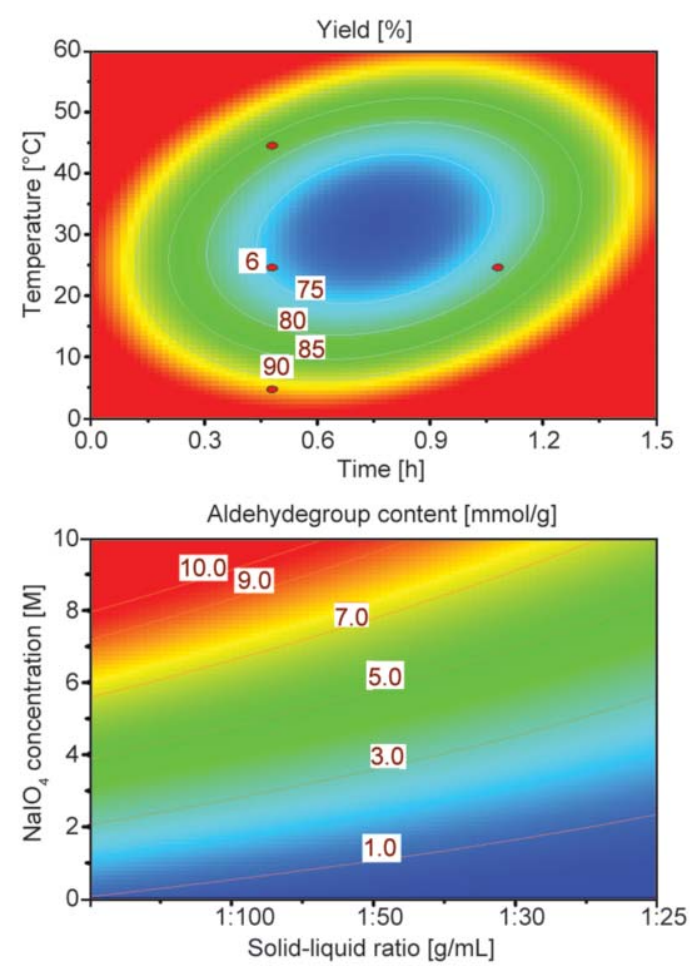

Figure 1. Response surface plots for maximum yield and aldehyde content of DACN: effects of temperature and reaction time on the yield [\%] (a), effects of $\mathrm{NaIO}_{4}$ concentration and solid-liquid ratio on the aldehyde content [mmol/g] of $\operatorname{DACN}(b)$ 


$$
\begin{aligned}
Y_{1} & =135.81-12.97 X_{1}-0.88 X_{2}-41.20 X_{3}- \\
& -1.30 X_{4}-8.88 \cdot 10^{-13} X_{1} X_{2}+3.70 \cdot 10^{-14} X_{1} X_{3}+ \\
& +2.46 \cdot 10^{-1} X_{1} X_{4}-2.22 \cdot 10^{-14} X_{2} X_{3}- \\
& -8.88 \cdot 10^{-16} X_{2} X_{4}-0.25 X_{3} X_{4}+259.30 X_{1}^{2}+ \\
& +1.46 X_{2}^{2}+18.93 X_{3}^{2}+0.02 X_{4}^{2}
\end{aligned}
$$

$$
\begin{aligned}
Y_{2} & =2.80+40.15 X_{1}+17.60 X_{2}-3.67 X_{3}-0.18 X_{4}- \\
& -666.67 X_{1} X_{2}-1.48 \cdot 10^{-14} X_{1} X_{3}- \\
& -2.96 \cdot 10^{-15} X_{1} X_{4}-1.27 \cdot 10^{-1} X_{2} X_{3}- \\
& -2.83 \cdot 10^{-16} X_{2} X_{4}-4.44 \cdot 10^{-17} X_{3} X_{4}+ \\
& +1648.15 X_{1}^{2}+14.90 X_{2}^{2}+1.83 X_{3}^{2}+ \\
& +2.04 \cdot 10^{-3} X_{4}^{2}
\end{aligned}
$$

where $Y_{1}$ and $Y_{2}$ are the yield and aldehyde content of DACN, whereas $X_{1}, X_{2}, X_{3}$ and $X_{4}$ are the coded variables for solid-liquid ratio, $\mathrm{NaIO}_{4}$ concentration, reaction time and temperature, respectively. In general, poor or misleading results may be produced by the exploration and optimization of a fitted response surface unless the model exhibited good fitness [24, 25]. Since the P-value of the model was less than 0.0001 , the model's fitness was good. The effects of the variables on the yield and aldehyde content of
DACN are shown in Figure 1. Based on the prediction of the computing program and taking the practical operating condition into consideration, the optimal conditions to obtain the highest yields are solidliquid ratio of 1: $50, \mathrm{NaIO}_{4}$ concentration of $0.5 \mathrm{M}$, reaction time of $0.5 \mathrm{~h}$, and temperature of $45^{\circ} \mathrm{C}$, while the optimal conditions to obtain the highest aldehyde contents are solid-liquid ratio of 1:100, $\mathrm{NaIO}_{4}$ concentration of $0.5 \mathrm{M}$, reaction time of $1.5 \mathrm{~h}$ and temperature of $60^{\circ} \mathrm{C}$. Thus, the experimental conditions should be chosen moderately according to the double response surface model, and the RDACN and SDACN could be obtained using this model under controllable conditions.

\subsection{Morphology of DACN}

In order to observe the morphologies of SDACN and RDACN, their FE-SEM images are clearly shown in Figure 2, in which the morphologies for different kinds of CNs are compared. MCC displayed rubbyshaped fragments with particle size of $15-30 \mu \mathrm{m}$ (Figure 2a). The CN-M (Figure 2b) and CN-S (Figure 3 a) both exhibited rod-like shape with average

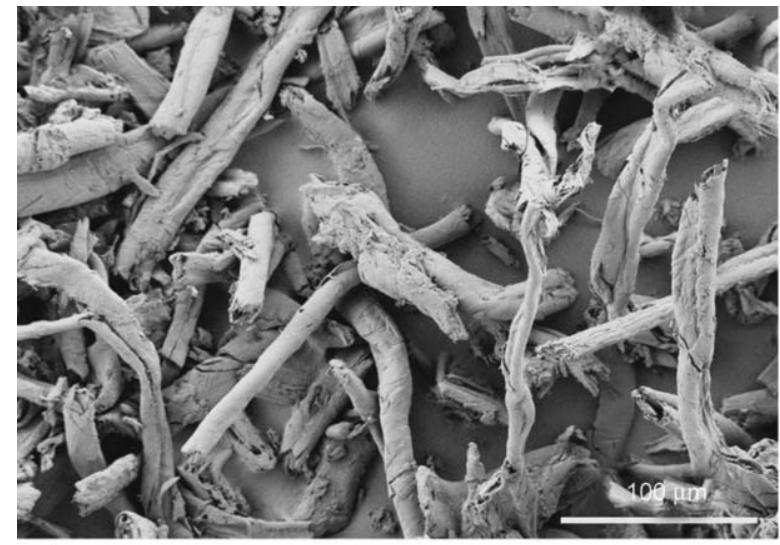

a)

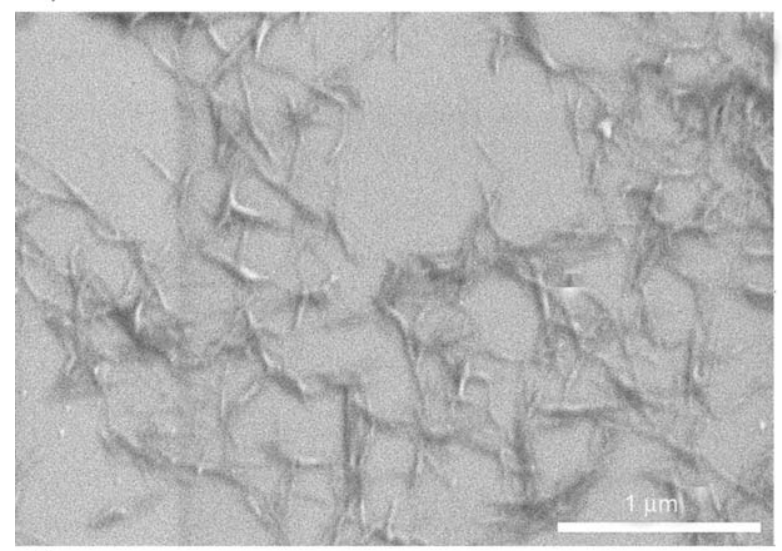

b)

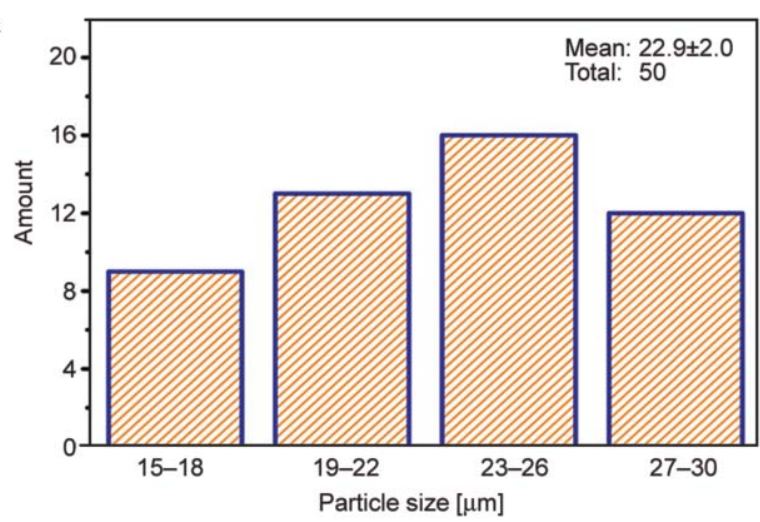

a')

CN-M

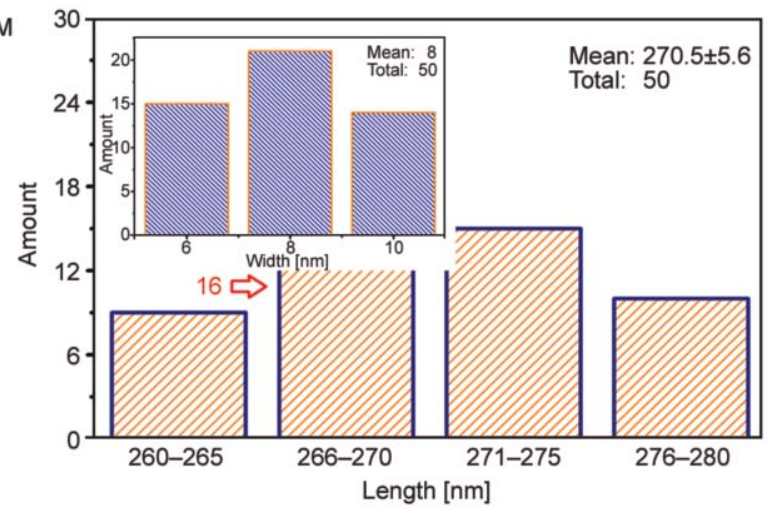

b')

Figure 2. FE-SEM images of MCC (a), CN-M (b), rod-like DACN and the particle size distribution (a', b') 

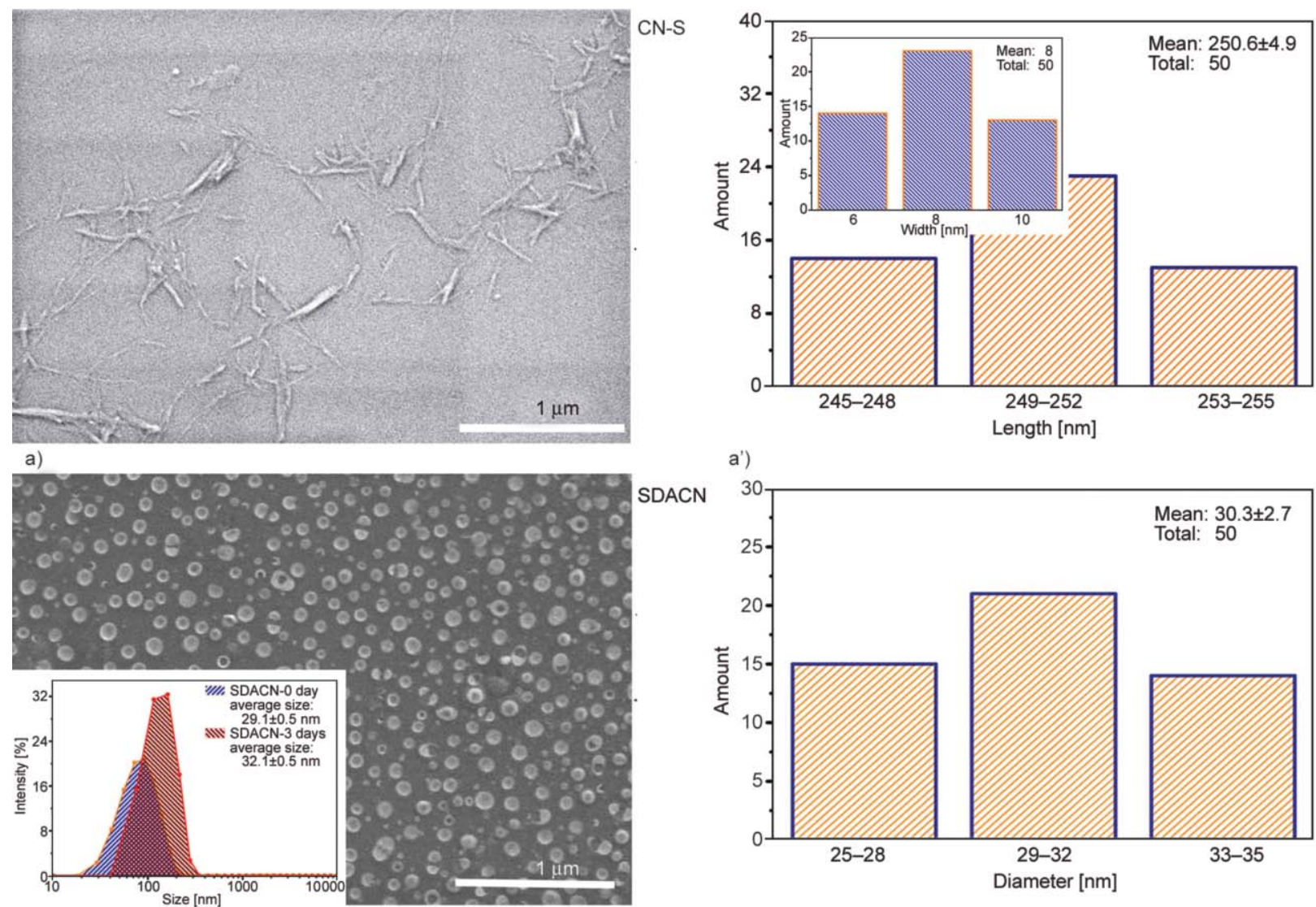

a'

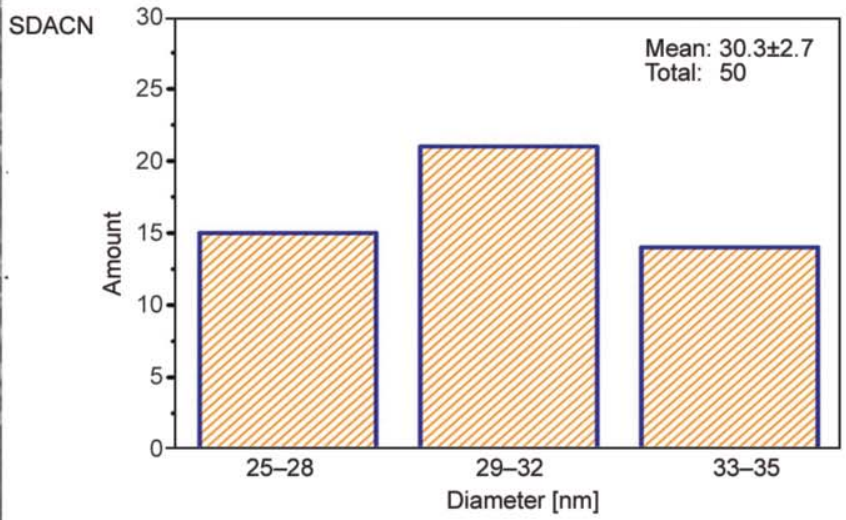

b)

b')
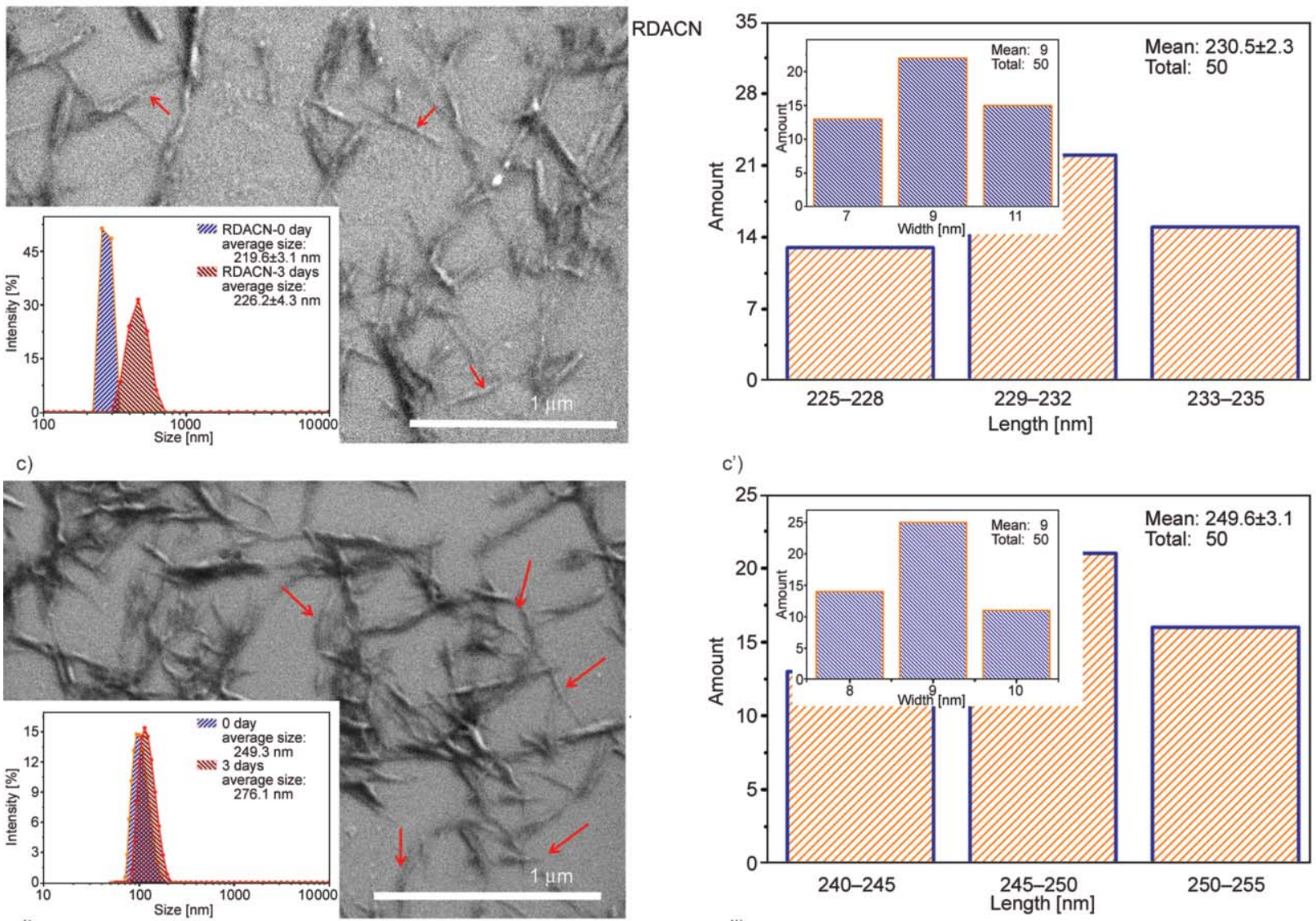

c')

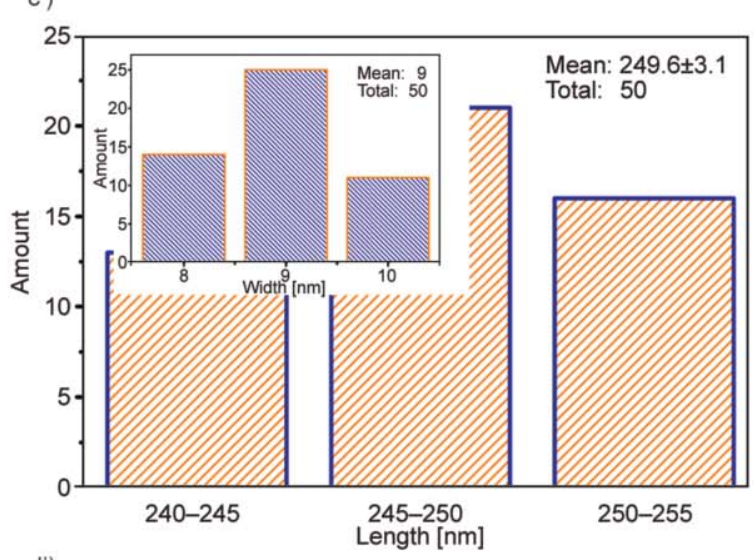

d')

Figure 3. FE-SEM images of CN-S (a), RDACN (b), SDACN (c), rod-like DACN (d) and the particle size distribution (a', b', c', d') 
length of $270.5 \pm 5.6,250.6 \pm 4.9 \mathrm{~nm}$, respectively, while the width for both samples was about $8 \mathrm{~nm}$. The similar dimension agreed well with previously reported work [7]. In particular, a good dispersion of $\mathrm{CN}-\mathrm{S}$ was found due to electrostatic repulsion of sulfate groups after the hydrolysis of sulfuric acid. In Figure 3b, SDACN showed spherical nanoparticles with a diameter of $25-35 \mathrm{~nm}$, while RDACN showed rod-like shape with average length of $230.5 \pm 2.3 \mathrm{~nm}$ and width of $9 \mathrm{~nm}$, respectively (Figure 3c). Furthermore, the particle sizes (freshly dispersed and kept in the room temperature for 3 days) of SDACN (insert in Figure 3b) and RDACN (insert in Figure 3c) were tested by the Nano ZS Malvern Zetasizer, and the results indicated the nanoscale size of SDACN and RDACN were obtained. Thus, the above mentioned results indicated that with the help of the oxidizing agent $\left(\mathrm{NaIO}_{4}\right)$, rod-like or spherical DACN can be regioselectively prepared by modulating the degree of oxidation. The $\mathrm{NaIO}_{4}$ oxidation as acidfree method showed great potential to prepare the CNs, which can replace common acid-hydrolyzed approach.

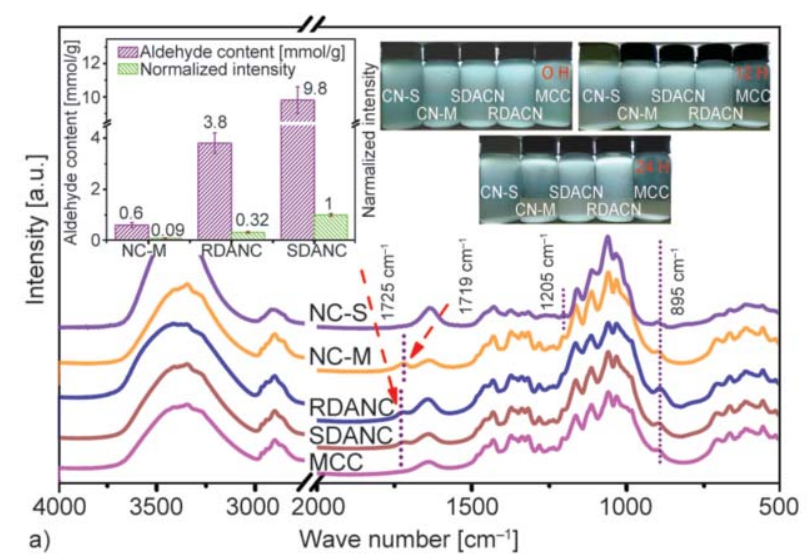

\subsection{Chemical structure of DACN}

FT-IR measurement was performed to determine the variation of surface chemical groups of different kinds of CN samples, and the FT-IR spectra are shown in Figure $4 \mathrm{a}$. Some characteristic peaks of cellulose at 3414, 2909, 1639, 1032-1056 and $895 \mathrm{~cm}^{-1}$ were assigned to $\mathrm{O}-\mathrm{H}$, symmetric $\mathrm{C}-\mathrm{H}$, absorbed moisture, $\mathrm{C}-\mathrm{O}-\mathrm{C}$ stretching vibration and $\beta$-glycosilic linkages between the sugar units, respectively [14, $18,26,27]$. For CN-S, a unique absorption band at $1205 \mathrm{~cm}^{-1}$ corresponded to $\mathrm{S}=\mathrm{O}$ stretching from sulfate groups was observed [7]. Because of the esterification reaction between hydroxyl groups on the surface of commercial MCC and $\mathrm{HCOOH}$, an obvious carbonyl $(\mathrm{C}=\mathrm{O})$ peak at $1719 \mathrm{~cm}^{-1}$ was found for $\mathrm{CN}-\mathrm{M}$ due to its surface formate groups (each formate group contained an aldehyde structure) $[2$, 20], while the DACN samples show new $\mathrm{C}=\mathrm{O}$ peak at $1725 \mathrm{~cm}^{-1}$ assigned to their aldehyde groups. Further, compared to $\mathrm{CN}-\mathrm{M}$, the DACN exhibited higher normalized intensity of $\mathrm{C}=\mathrm{O}$ peak, indicating more aldehyde groups were introduced into DACNs by $\mathrm{NaIO}_{4}$ oxidation than mixed acid hydrolysis. Similar

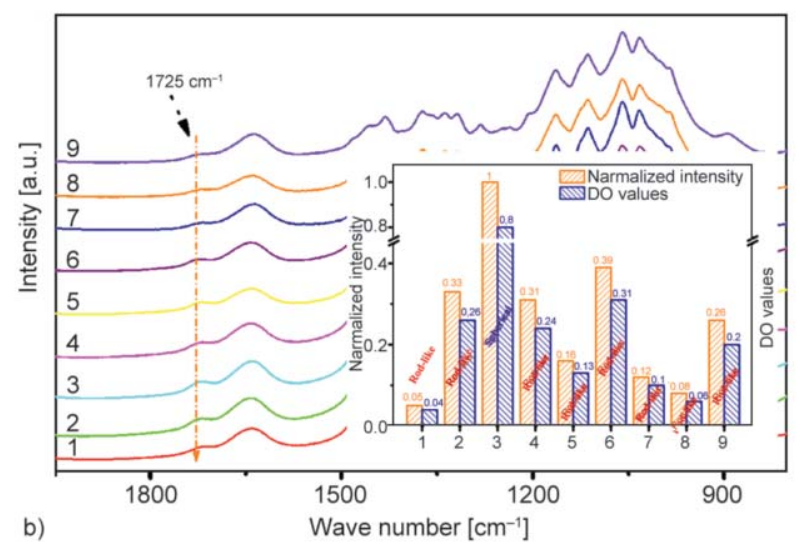

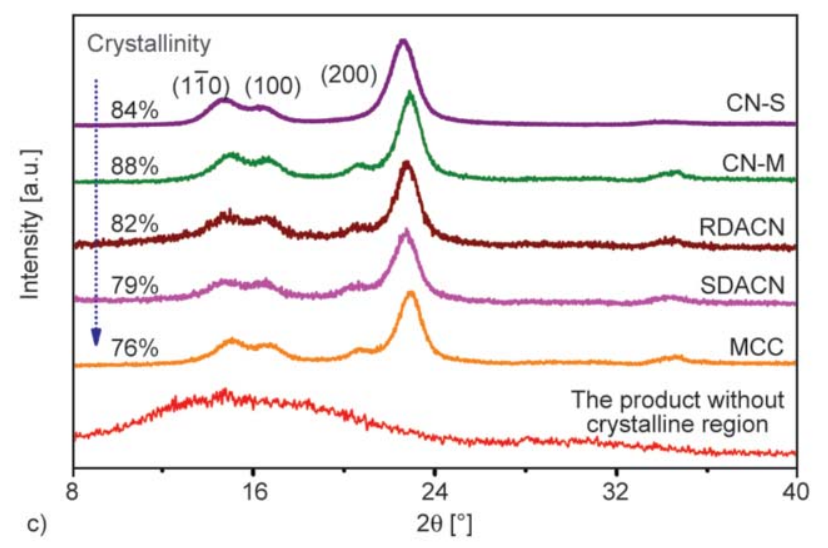

Figure 4. FT-IR spectra (normalization intensity of carbonyl peak at 1719 and $1725 \mathrm{~cm}^{-1}$ ) of CNs and MCC (a), FT-IR spectra (b) of nine orthogonal experiment groups (c), and XRD patterns of CNs and MCC 
phenomenon was observed in $\mathrm{NaIO}_{4}$ oxidation of CNs (natural cellulose fibers) [14]. When the skeleton band of cellulose at $800-900 \mathrm{~cm}^{-1}$ was fixed, normalization intensity of aldehyde $\mathrm{C}=\mathrm{O}$ peak for $\mathrm{DACNs}$ can be used to qualitatively comparison analysis. Moreover, the SDACN showed the higher normalized intensity for $\mathrm{C}=\mathrm{O}$ peak than that of $\mathrm{RDACN}$, suggesting that spherical nanoparticles with high specific surface area were more susceptible to be attacked by $\mathrm{NaIO}_{4}$, leading to the formation of more aldehyde groups. Meanwhile, the FT-IR spectra, normalized intensity for $\mathrm{C}=\mathrm{O}$ peak at $1725 \mathrm{~cm}^{-1}$ and corresponding OD values of DACNs ( 9 samples from orthogonal experiment groups) prepared by $\mathrm{NaIO}_{4}$ oxidation were shown in Figure 4b. The results of normalized intensity for $\mathrm{C}=\mathrm{O}$ peak for $\mathrm{CNs}$ can support above results. Additionally, the DACNs prepared by $\mathrm{NaIO}_{4}$ oxidation exhibited as good suspension stability as $\mathrm{CN}-\mathrm{M}$ and $\mathrm{CN}-\mathrm{S}$ samples (insert in Figure 4a).

\subsection{Crystal structure and crystallinity of DACN}

The XRD spectra for MCC and $\mathrm{CN}$ samples were presented in Figure $4 \mathrm{c}$. MCC and the other CNs possessed typical peaks of cellulose I with main peaks at $2 \theta=14.5,16.5$, and $22.6^{\circ}$, which assigned to the crystalline planes of (110), (110) and (200), respectively $[1,2,14,18]$. By using Segal's method [28], the crystallinity of MCC, CN-S and CN-M were 76, 84 and $88 \%$, respectively. Compared to CN-S and $\mathrm{CN}-\mathrm{M}$, a slight reduction in crystallinity (82\%) was found for RDACN and SDACN (79\%). The results showed that all CNs have higher crystallinity than
MCC, which indicating that parts of MCC residual amorphous phase have been dissolved by various treatments (mixed acid $(\mathrm{HCl} / \mathrm{HCOOH})$, sulfuric acid, $\mathrm{NaIO}_{4}$ oxidation). For acid hydrolysis, the fabricating process for $\mathrm{CNs}$ was aimed at breaking the $\beta-1,4$-glycosidic bonds on the amorphous region of MCC, while the oxidation process would open glucopyranose chains in crystalline or amorphous regions and increase the solubility (Figure 5), which resulting in lower degree of crystallinity than acid hydrolysis process. The decreased crystallinity was ascribed to the higher opened glucopyranose rings (higher DO values) and the higher destruction of ordered $\mathrm{CNs}$ structure, under violent condition of $\mathrm{NaIO}_{4}$ oxidation, and the nanocrystals with the selective orientation causing a reduction in diffraction peak intensity from some Bragg planes [18]. Generally, the higher the DO value was, the lower the crystallinity was. Moreover, the higher crystallinity of CN-M was attributed to only amorphous regions of cellulose materials attacked by acid hydrolysis and esterification reactions, without opened glucopyranose rings in crystalline regions.

\subsection{Thermal stability of DACN}

TGA and DTG curves (Figure 6) revealed the thermal stability for MCC and $\mathrm{CN}$ samples. Comparing with MCC (onset degradation temperature $\left(T_{0}\right)$ of $325.3^{\circ} \mathrm{C}$ ), the $\mathrm{CN}-\mathrm{M}$ owned the higher $T_{0}$ of $346.9^{\circ} \mathrm{C}$, the other CNs samples had lower $T_{0}$ values. Especially, CN-S showed very low $T_{0}$ value of $208.1{ }^{\circ} \mathrm{C}$ because of the existence of sulfate groups on cellulose surface [7, 28], while the RDACN and SDACN had higher $T_{0}$ value of 281.6 and $222.1^{\circ} \mathrm{C}$, respec-

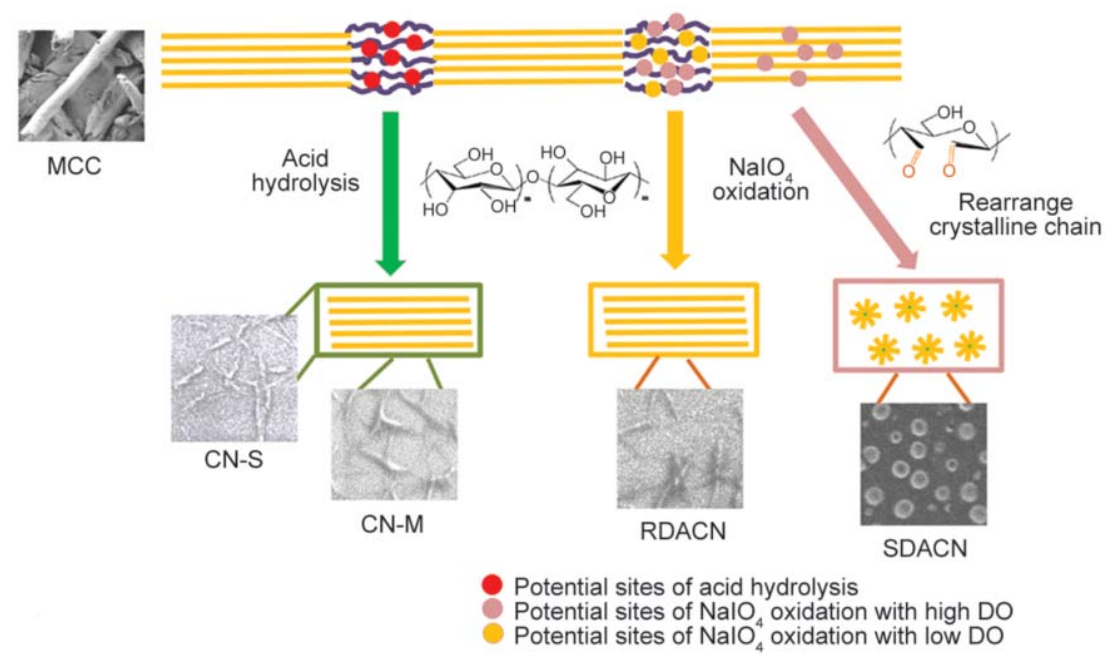

Figure 5. $\mathrm{NaIO}_{4}$ oxidation and acid hydrolysis mechanism schema of CNs 

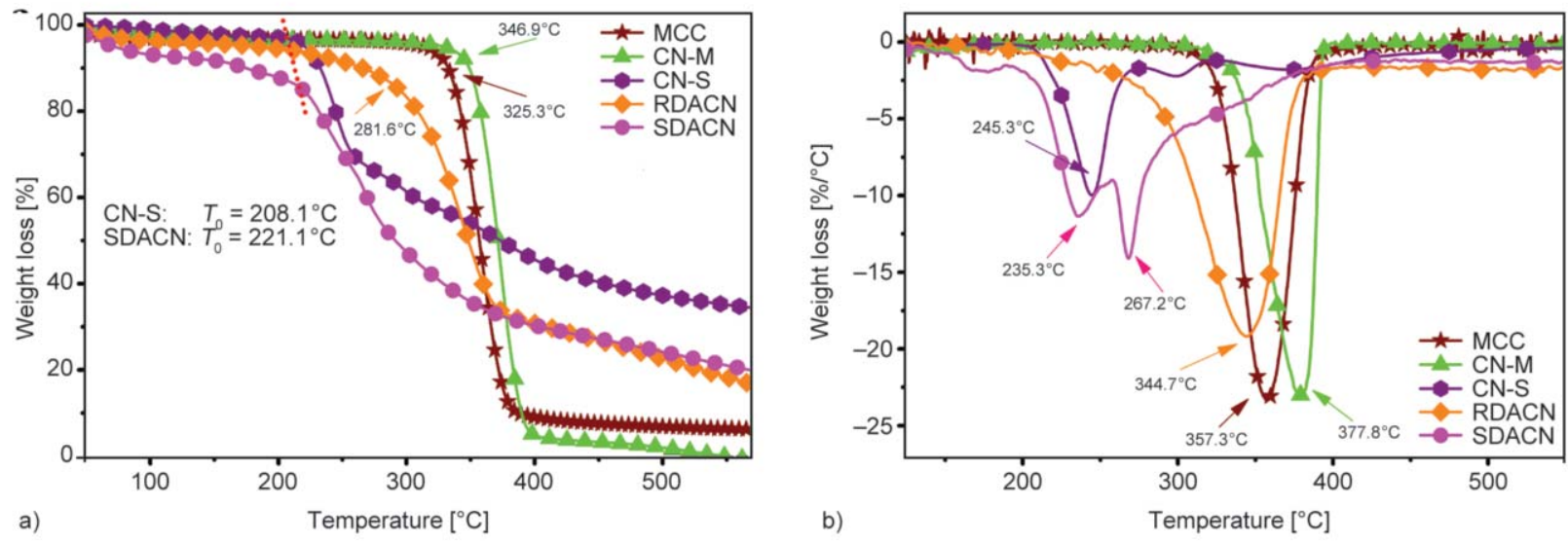

Figure 6. TGA (a) and DTG (b) curve of CN-S, CN-M, RDACN, SDACN and MCC

tively. A similar trend was found for maximum degradation temperature $\left(T_{\max }\right)$ of the samples. For clear observation, the thermal stability data $\left(T_{0}, T_{\max }\right.$, $T_{\mathrm{f}}$ (complete degradation temperature)) were shown in Table 4. In addition, the first derivative of the weight loss curve with respect to temperature (DTG) was shown in Figure 6b. It can be observed that MCC, $\mathrm{CN}-\mathrm{M}$ and RDACN owned the single step maximum degradation peaks at $357.3,377.8$ and $344.7^{\circ} \mathrm{C}$, respectively. However, CN-S and SDACN started to degrade at lower temperature and exhibited with two main peaks. For $\mathrm{CN}-\mathrm{S}$ with sulfate groups, the degradation occurred within a wider temperature range and showed three well separated pyrolysis processes: the first one appeared around $196.9-275.0^{\circ} \mathrm{C}$, the second one was around $277.0-324.7^{\circ} \mathrm{C}$, and the other occurred around $325.0-443.9^{\circ} \mathrm{C}$. The multiple degradation peaks exhibited in $\mathrm{CN}-\mathrm{S}$ curve were attributed to the wide size distribution and the introduction of sulfate groups during sulfuric acid hydrolysis of MCC with possible different sulfonation degrees [7, $28]$. On the other hand, SDACN showed two degradation peaks at 235.3 and $267.2^{\circ} \mathrm{C}$. This was due to that the dialdehyde modified SDACNs chains did not form the hemiacetal linkage during the first $\left(195.5-259.8^{\circ} \mathrm{C}\right)$ degradation process. The second degradation process $\left(259.8-411.4^{\circ} \mathrm{C}\right)$ was ascribed to the degradation of cellulose skeleton for the SDACN. Therefore, the $\mathrm{CNs}$ prepared by $\mathrm{NaIO}_{4}$ oxidation had better thermal stability than that for $\mathrm{H}_{2} \mathrm{SO}_{4}$ hy- drolyzed one, but poorer than that of CN-M. In addition, RDACN showed the higher degradation temperature than that of SDACN, probably resulting from low degree of oxidation, surface morphology and crystallinity.

\subsection{Properties for $\mathrm{CN}-\mathrm{Ag}$ nanohybrids}

In general, the more aldehyde groups on the $\mathrm{CNs}$ surface is beneficial to anchor more metal nanoparticles via redox reaction, thus the SDACN with highest aldehyde content, RDACN and CN-M with low aldehyde content were selected to investigate the morphology and antibacterial activity for resulting $\mathrm{CN}-\mathrm{Ag}$ nanohybrids. It is found that more $\mathrm{Ag}$ nanoparticles $(29.6 \%)$ with diameter of $30 \pm 4 \mathrm{~nm}$ on the SDACN-Ag-0.85 are observed, whereas the less Ag nanoparticles with diameter of $33 \pm 4$ and $35 \pm 5 \mathrm{~nm}$ were fixed on the RDACN-Ag-0.85 (23.9\%) and CNM-Ag-0.85 (21.6\%) surfaces, respectively, shown in Figure $7 \mathrm{~d}$. The XRD patterns (Figure 7e) of CN-MAg-0.85, RDACN-Ag-0.85 and SDACN-Ag-0.85 showed four diffraction peaks at $2 \theta=38.3,44.3$, 64.5 and $77.5^{\circ}$ assigning to the (111), (200), (220) and (311) planes of cubic Ag nanoparticles [1,20]. Further, the antibacterial activities for $\mathrm{CN}-\mathrm{Ag}$ nanohybrids against $S$. aureus and $E$. coli by formation of zone of inhibitions are shown in Figure 7f. All the nanohybrids gave extremely strong activities against both the Gram-positive (S. aureus) and Gram-negative (E. coli) species. Moreover, the SDACN-Ag-0.85

Table 4. Thermal stability data $\left(T_{0}, T_{\max }, T_{\mathrm{f}}\right)$ of MCC, CN-M, CN-S, RDACN and SDACN

\begin{tabular}{|ll|c|c|c|c|c|}
\hline & & $\mathbf{M C C}$ & $\mathbf{C N}-\mathbf{M}$ & $\mathbf{C N}-\mathbf{S}$ & RDACN & SDACN \\
\hline$T_{0}$ & {$\left[{ }^{\circ} \mathrm{C}\right]$} & 325.3 & 346.9 & 208.1 & 281.6 & 222.1 \\
\hline$T_{\max }\left[{ }^{\circ} \mathrm{C}\right]$ & 357.3 & 377.8 & $245.3 / 294.1 / 374.6$ & 344.7 & $235.3 / 267.2$ \\
\hline$T_{\mathrm{f}}$ & {$\left[{ }^{\circ} \mathrm{C}\right]$} & 373.4 & 390.3 & 363.9 & 367.1 & 341.5 \\
\hline
\end{tabular}



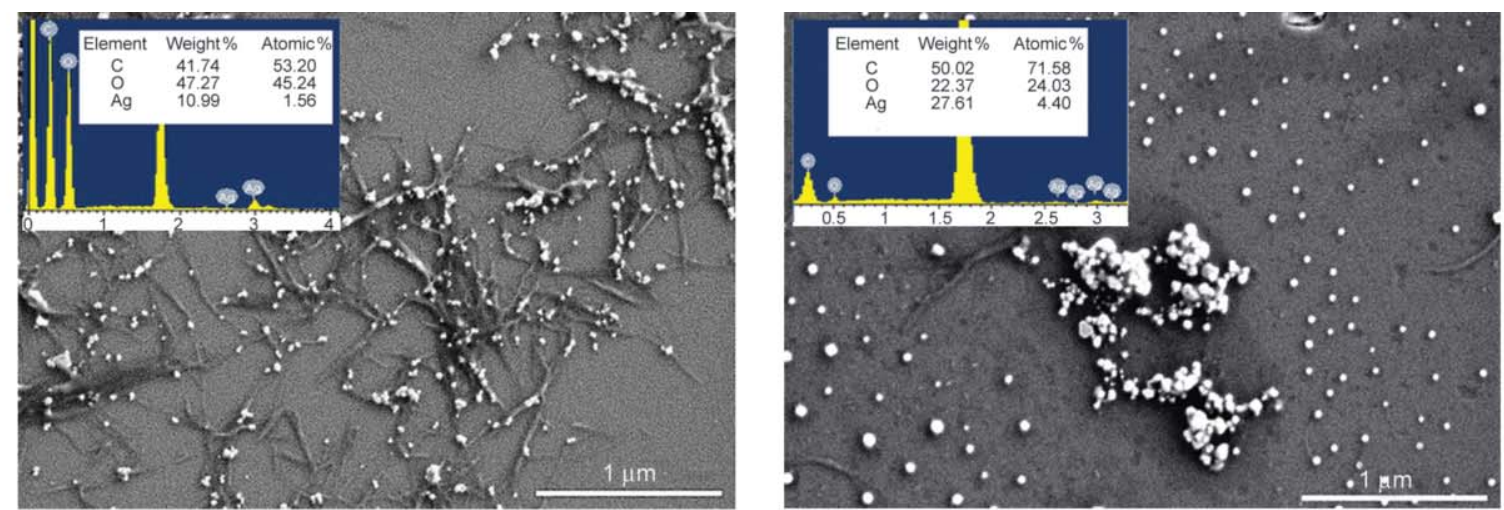

a)

b)

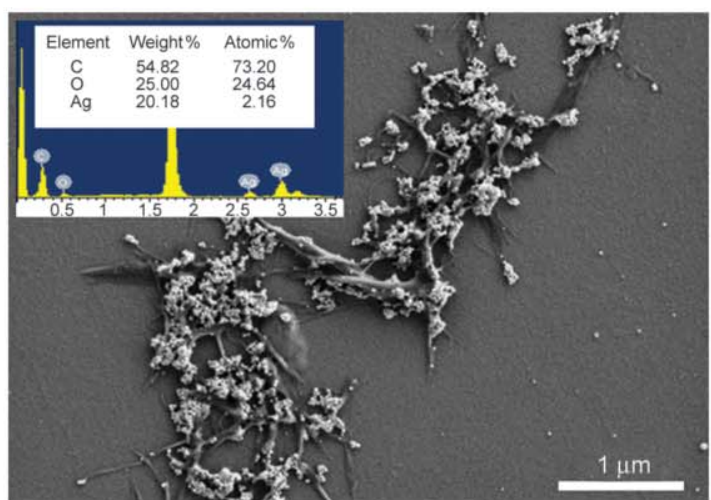

c)
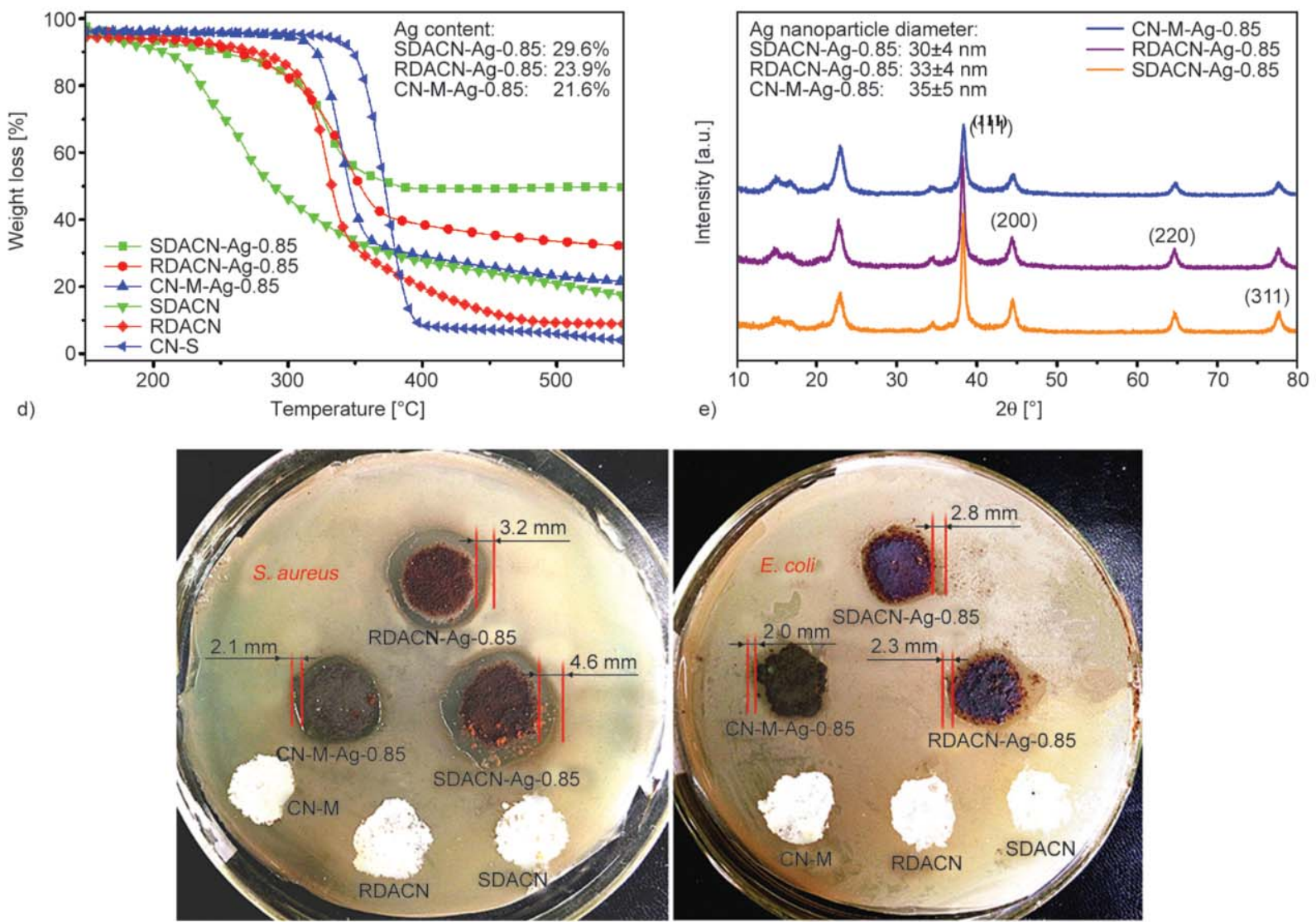

f)

Figure 7. FE-SEM images of CN-M-Ag-0.85 (a), SDACN-Ag-0.85 (b), RDACN-Ag-0.85 nanohybrids (c) and their TGA curves (d), XRD patterns (e), antibacterial abilities against $S$. aureus and E. coli (f) 
presented the largest inhibition zone against $S$. aureus and E. coli ( 4.6 and $2.8 \mathrm{~mm}$ ) than RDACN-Ag-0.85 (3.2 and $2.3 \mathrm{~mm}$ ) and CN-M-Ag-0.85 (2.1 and $2.0 \mathrm{~mm}$ ), suggesting that the large amount of aldehyde groups on SDACN reduced more $\mathrm{Ag}^{+}$into $\mathrm{Ag}^{0}$ nanoparticles, leading to the high antibacterial activity $[1,2,20]$.

\section{Conclusions}

Spherical and rod-like DACN can be optimized and regioselectively extracted from MCC via one-step $\mathrm{NaIO}_{4}$ oxidation using a novel double response surface model. Both SDACN with the high aldehyde content of $9.8 \mathrm{mmol} / \mathrm{g}$ and RDACN with relatively low aldehyde content of $3.8 \mathrm{mmol} / \mathrm{g}$ possessed cellulose I crystal structure. Moreover, RDACN and SDACN showed the better thermal stability than $\mathrm{CN}-\mathrm{S}\left(\mathrm{H}_{2} \mathrm{SO}_{4}\right.$ hydrolysis), but lower than $\mathrm{CN}-\mathrm{M}$ (hydrochloric/formic hydrolysis) due to less destruction of the ordered cellulose structure. In addition, SDACN can act as the reductant for anchoring more Ag nanoparticles, and thus the resultant SDACNAg-0.85 nanohybrids demonstrated the highest antibacterial activity against both Gram-negative $E$. coil and Gram-positive $S$. aureus. Thus, one-step $\mathrm{NaIO}_{4}$ oxidation in this study as acid-free route showed more advantages than acid hydrolysis methods, and the DACN may have potential applications in functional papers, sensors, and bioimaging for large-scale production of cellulose-based nanocomposites.

\section{Acknowledgements}

The work was financially supported by the National Natural Science Foundation of China (51403187), the public technology research plan of Zhejiang Province, China under Grant No. 2015C33111, and '521' Talent Project of Zhejiang Sci-Tech University and Open fund in Top Priority Discipline of Zhejiang Province in Zhejiang Sci-Tech University (2015YXQN04, 2016YXQN07, 2015YXQN11).

\section{References}

[1] Yu H., Sun B., Zhang D., Chen G., Yang X., Yao J.: Reinforcement of biodegradable poly(3-hydroxybutyrateco-3-hydroxyvalerate) with cellulose nanocrystal/silver nanohybrids as bifunctional nanofillers. Journal of Materials Chemistry B, 2, 8479-8489 (2014).

DOI: $10.1039 / \mathrm{C} 4 \mathrm{~TB} 01372 \mathrm{G}$
[2] Yu H-Y., Qin Z-Y., Sun B., Yan C. F., Yao J-M.: Onepot green fabrication and antibacterial activity of thermally stable corn-like CNC/Ag nanocomposites. Journal of Nanoparticle Research, 16, 2202/1-2202/12 (2014). DOI: 10.1007/s11051-013-2202-4

[3] Padalkar S., Capadona J. R., Rowan S. J., Weder C., Moon R. J., Stanciu L. A.: Self-assembly and alignment of semiconductor nanoparticles on cellulose nanocrystals. Journal of Materials Science, 46, 5672-5679 (2011). DOI: $10.1007 / \mathrm{s} 10853-011-5518-4$

[4] Yang X., Cranston E. D.: Chemically cross-linked cellulose nanocrystal aerogels with shape recovery and superabsorbent properties. Chemistry of Materials, 26, 6016-6025 (2014).

DOI: $10.1021 / \mathrm{cm} 502873 \mathrm{c}$

[5] Wang H. R., He J. L., Zhang M. Z., Tam K. C., Ni P. H.: A new pathway towards polymer modified cellulose nanocrystals via a 'grafting onto' process for drug delivery. Polymer Chemistry, 6, 4206-4209 (2015). DOI: $10.1039 / C 5 P Y 00466 \mathrm{G}$

[6] Cao S-L., Li X-H., Lou W-Y., Zong M-H.: Preparation of a novel magnetic cellulose nanocrystal and its efficient use for enzyme immobilization. Journal of Materials Chemistry B, 2, 5522-5530 (2014).

DOI: $10.1039 / \mathrm{C} 4 \mathrm{~TB} 00584 \mathrm{H}$

[7] Yu H., Qin Z., Liang B., Liu N., Zhou Z., Chen L.: Facile extraction of thermally stable cellulose nanocrystals with a high yield of $93 \%$ through hydrochloric acid hydrolysis under hydrothermal conditions. Journal of Materials Chemistry A, 1, 3938-3944 (2013). DOI: $10.1039 /$ C3TA01150J

[8] Satyamurthy P., Vigneshwaran N.: A novel process for synthesis of spherical nanocellulose by controlled hydrolysis of microcrystalline cellulose using anaerobic microbial consortium. Enzyme and Microbial Technology, 52, 20-25 (2013).

DOI: $10.1016 /$ j.enzmictec.2012.09.002

[9] Li M-C., Wu Q., Song K., Qing Y., Wu Y.: Cellulose nanoparticles as modifiers for rheology and fluid loss in bentonite water-based fluids. ACS Applied Materials and Interfaces, 7, 5006-5016 (2015).

DOI: $10.1021 /$ acsami.5b00498

[10] Montanari S., Roumani M., Heux L., Vignon M. R.: Topochemistry of carboxylated cellulose nanocrystals resulting from TEMPO-mediated oxidation. Macromolecules, 38, 1665-1671 (2005).

DOI: $10.1021 / \mathrm{ma} 048396 \mathrm{c}$

[11] Paralikar S. A., Simonsen J., Lombardi J.: Poly(vinyl alcohol)/cellulose nanocrystal barrier membranes. Journal of Membrane Science, 320, 248-258 (2008). DOI: $10.1016 /$ j.memsci.2008.04.009

[12] Cheng M., Qin Z. Y., Liu Y., Qin Y., Li T., Chen L., Zhu M.: Efficient extraction of carboxylated spherical cellulose nanocrystals with narrow distribution through hydrolysis of lyocell fibers by using ammonium persulfate as an oxidant. Journal of Materials Chemistry A, 2, 251-258 (2014).

DOI: $10.1039 / \mathrm{C} 3 \mathrm{TA} 13653 \mathrm{~A}$ 
[13] Dash R., Ragauskas A. J.: Synthesis of a novel cellulose nanowhisker-based drug delivery system. RSC Advances, 2, 3403-3409 (2012).

DOI: $10.1039 / \mathrm{C} 2 \mathrm{RA} 01071 \mathrm{~B}$

[14] Sun B., Hou Q., Liu Z., Ni Y.: Sodium periodate oxidation of cellulose nanocrystal and its application as a paper wet strength additive. Cellulose, 22, 1135-1146 (2015).

DOI: $10.1007 / \mathrm{s} 10570-015-0575-5$

[15] Huang R., Liu Z., Sun B., Fatehi P.: Preparation of dialdehyde cellulose nanocrystal as an adsorbent for creatinine. The Canadian Journal of Chemical Engineering, 94, 1435-1441 (2016).

DOI: $10.1002 /$ cjce. 22523

[16] Yang H., Chen D., van de Ven T. G. M.: Preparation and characterization of sterically stabilized nanocrystalline cellulose obtained by periodate oxidation of cellulose fibers. Cellulose, 22, 1743-1752 (2015).

DOI: $10.1007 / \mathrm{s} 10570-015-0584-4$

[17] Yang H., Tejado A., Alam N., Antal M., van de Ven T. G. M.: Films prepared from electrosterically stabilized nanocrystalline cellulose. Langmuir, 28, 7834-7842 (2012).

DOI: $10.1021 / 1 \mathrm{a} 2049663$

[18] Yang H., Alam M. N., van de Ven T. G. M.: Highly charged nanocrystalline cellulose and dicarboxylated cellulose from periodate and chlorite oxidized cellulose fibers. Cellulose, 20, 1865-1875 (2013).

DOI: $10.1007 / \mathrm{s} 10570-013-9966-7$

[19] Grate J. W., Mo K-F., Shin Y., Vasdekis A., Warner M. G., Kelly R. T., Orr G., Hu D., Dehoff K. J., Brockman F. J., Wilkins M. J.: Alexa fluor-labeled fluorescent cellulose nanocrystals for bioimaging solid cellulose in spatially structured microenvironments. Bioconjugate Chemistry, 26, 593-601 (2015).

DOI: $10.1021 /$ acs.bioconjchem.5b00048

[20] Drogat N., Granet R., Sol V., Memmi A., Saad N., Koerkamp C. K., Bressollier P., Krausz P.: Antimicrobial silver nanoparticles generated on cellulose nanocrystals. Journal of Nanoparticle Research, 13, 1557-1562 (2011).

DOI: $10.1007 / \mathrm{s} 11051-010-9995-1$
[21] Kim U-J., Wada M., Kuga S.: Solubilization of dialdehyde cellulose by hot water. Carbohydrate Polymers, 56, 7-10 (2004).

DOI: 10.1016/j.carbpol.2003.10.013

[22] Wu M., Kuga S., Huang Y.: Quasi-one-dimensional arrangement of silver nanoparticles templated by cellulose microfibrils. Langmuir, 24, 10494-10497 (2008). DOI: $10.1021 / 1 \mathrm{a} 801602 \mathrm{k}$

[23] Kim U-J., Kuga S., Wada M., Okano T., Kondo T.: Periodate oxidation of crystalline cellulose. Biomacromolecules, 1, 488-492 (2000).

DOI: $10.1021 / \mathrm{bm} 0000337$

[24] Tang L-R., Huang B., Ou W., Chen X-R., Chen Y-D.: Manufacture of cellulose nanocrystals by cation exchange resin-catalyzed hydrolysis of cellulose. Bioresource Technology, 102, 10973-10977 (2011). DOI: 10.1016/j.biortech.2011.09.070

[25] Sun B., Yu H-Y., Zhou Y., Huang Z., Yao J-M.: Singlestep extraction of functionalized cellulose nanocrystal and polyvinyl chloride from industrial wallpaper wastes. Industrial Crops and Products, 89, 66-77 (2016). DOI: $10.1016 /$ j.indcrop.2016.04.040

[26] Visanko M., Liimatainen H., Sirvio J. A., Heiskanen J. P., Niinimaki J., Hormi O.: Amphiphilic cellulose nanocrystals from acid-free oxidative treatment: Physicochemical characteristics and use as an oil-water stabilizer. Biomacromolecules, 15, 2769-2775 (2014). DOI: $10.1021 / \mathrm{bm} 500628 \mathrm{~g}$

[27] Keshk S. M. A. S.: Homogenous reactions of cellulose from different natural sources. Carbohydrate Polymers, 74, 942-945 (2008). DOI: 10.1016/j.carbpol.2008.05.022

[28] Kargarzadeh H., Ahmad I., Abdullah I., Dufresne A., Zainudin S. Y., Sheltami R. M.: Effects of hydrolysis conditions on the morphology, crystallinity, and thermal stability of cellulose nanocrystals extracted from kenaf bast fibers. Cellulose, 19, 855-866 (2012).

DOI: $10.1007 / \mathrm{s} 10570-012-9684-6$ 